\title{
Creating Effective Partnerships in Ecosystem-Based Management: A Culture of Science and Management
}

\author{
Carlie S. Wiener, ${ }^{1}$ Malia A. J. Rivera, ${ }^{1}$ Robert J. Toonen, ${ }^{1}$ Jo-Ann C. Leong, ${ }^{1}$ \\ Randall K. Kosaki, ${ }^{2}$ Stephen Karl, ${ }^{1}$ Kaylene Keller, ${ }^{2}$ and Hoku Johnson ${ }^{2}$ \\ ${ }^{1}$ Hawai'i Institute of Marine Biology, School of Ocean and Earth Science and Technology, University of Hawai'i at Mānoa, \\ P.O. Box 1346, Kāne'ohe, HI 96744, USA \\ ${ }^{2}$ Papahānaumokuākea Marine National Monument, 6600 Kalaniana'ole Hwy, no. 300 Honolulu, HI 96825, USA
}

Correspondence should be addressed to Carlie S. Wiener, cwiener@hawaii.edu

Received 16 June 2010; Revised 3 September 2010; Accepted 24 October 2010

Academic Editor: Benjamin S. Halpern

Copyright (C) 2011 Carlie S. Wiener et al. This is an open access article distributed under the Creative Commons Attribution License, which permits unrestricted use, distribution, and reproduction in any medium, provided the original work is properly cited.

\begin{abstract}
An ecosystem-based management research partnership between the Hawaici Institute of Marine Biology and Office of National Marine Sanctuaries, specifically with the Northwestern Hawaiian Islands Coral Reef Ecosystem Reserve and, later, the Papahānaumokuākea Marine National Monument, provides a case study to analyze integration of scientific research into management plans through collaborative communications. Ecosystem-based management seeks input from disparate stakeholders and requires effective communication systems for the public, science, and management partners that bypass differences in organizational culture and communication styles. Here, we examine a successful partnership within the framework of ecosystembased management to survey and evaluate cultural differences, understand what facilitates collaborative communication, highlight factors that impede a successful partnership, and identify areas for improvement. Effective communication has been achieved through an analysis of the organizations cultures and structures to better define communication links. Although specific differences were noted in organization and style, successful integration was accomplished through techniques such as the development of symposia and semiannual reports. This paper will explore the organizational culture analysis and structure evaluation, which are components of a larger study. This science management integration project is an example of how organizational analysis can lead to recommendations for improved communication and integration of science and management.
\end{abstract}

\section{Introduction}

Single-species management has often failed to deal with the multitude of issues associated with complex, isolated, and large ecosystems. To address this, ecosystem-based management (EBM) has emerged, which uses a holistic perspective to focus protection on a large area as opposed to specific species. Marine EBM has now been broadly accepted in policy, science, and management as crucial for effective marine conservation and resource preservation [1-5]. A key component to successful EBM programs is the integration of science into the management process. Since EBM has grown at such a rapid pace, it is necessary to ensure that the practices of science and management work together. This is often a challenge because each operates by and responds to different mandates, time scales, and authorities. The sciencepolicy continuum can be improved through practical management strategies that are capable of incorporating policy-relevant research [6]. EBM relies heavily on scientific inquiry for an understanding of the status and changes related to the managed environment. As science management integration becomes more commonplace, issues associated with the respective cultures of each field arise. Even though managers and scientists agree on the necessity of incorporating science into management, very little research has been conducted to examine how this can be accomplished in practice. The recent increase in large-scale marine protected areas throughout the Pacific and use of EBM has demonstrated the need for showcasing successful examples of science management integration. This paper 
will examine how organization structure, communication styles, and cultural differences can impact integration of science and management. It also examines how analysis of these differences has been applied to the Northwestern Hawaiian Islands Research Partnership (NWHI-RP) and the analysis recommendations. The NWHI-RP will be used as a case study applying businesses management models to better understand the differences within science and management.

\section{Review of Science Management Integration}

The current literature on the relationship between science and management has repeatedly called for more communication between scientists and managers $[7,8]$. This consensus solution is in principal a practical and appropriate one. However, it lacks a true analysis of the underlying issues and fails to develop detailed recommendations relating to the integration of science and management relationships or communication methods. The ability for scientists to communicate with managers has been referenced as a common struggle, particularly within EBM [9-13]. For example, in 1999, the UNESCO World Conference on Science adopted a declaration on the use of scientific data, which included recommendations of frequent science communications training. This was echoed in 2005, when the George Wright Society, a nonprofit association devoted to scientific and cultural values of protected areas, made additional requests including improved communication, incorporation of management needs into ecological monitoring, and inclusion of scientific results into management and planning. Recently, the Marine Conservation Biology Institute (MCBI) also expressed similar concerns in their report Recommendations for the Management of the New Pacific Remote Monuments [14]. While there have been many calls to action, the NWHI$\mathrm{RP}$ has been implementing collaborative communication mechanisms to integrate science and management since the partnership was initiated five years ago. The partnership provides an excellent model of how to accomplish these illdefined goals and will be further explored in this paper.

How scientists convey their research to managers, policy makers, and the public plays an important role in decision making within EBM [15]. In the last two years, the US federal government has released two planning documents that outline the need for both science in management and the further development of EBM. The White House Council on Environmental Quality Final Recommendations of the Interagency Ocean Policy Task Force [5] and the NOAA Coral Reef Conservation Program Roadmap for the Future [16] both present EBM as a critical technique for handling future ocean conservation. With plans to increase EBM, greater reliance on scientific research will be needed as a source for planning information. Therefore, a better understanding of the science-management connection is required to enhance accountability and relevance in EBM partnerships [15]. Over the last ten years, as scientists have been encouraged to participate in meetings, where policy and management issues are discussed, increasing demands have been placed on scientists to translate their research to management [6].
Unfortunately, there has been limited exploration or testing of this in case studies. A detailed literature search was completed in 2009 exploring the concepts of communications and integration in EBM. While a considerable amount of work has been published on the subject, few studies have developed pragmatic and practical applications or examples. As collaborative, ecosystem-based approaches to management increase in frequency, partnership evaluations are needed to better understand the institutional challenges surrounding EBM [17]. Looking at organizational design and culture is central to improving understanding of the relationship between science and values in management decision making [17].

2.1. Review of Barriers to Effective Communication. The published literature calls for two-way communications between scientists and managers $[6,13,18]$. Standard, one-way communication from scientists to managers has lost popularity due to the ineffective relationships that have developed and the general disfavor of linear information [6]. Collaboration through science management communications has become more common, but there continues to be transmission issues that require examination [12]. Science can play a large role in the management and policy process, particularly with more science-driven management techniques such as EBM. While joint communication allows for a better exchange of information between management and science parties, there are still challenges due to the nature of these disciplines. One of the common challenges has been identified as the language in use, which can impede comprehension of the information presented. Both science and management communications need to be liberated from technical language and abbreviations in writing, while maintaining the integrity and purpose of the source information $[13,18]$.

The management and policy literature has suggested that scientists should report in a more general and practical format for those that lack training in the scientific field and to facilitate a comprehensible platform for nonscience team members to better understand the materials [9]. Scientific data are now being used in the design of management tools and in identifying knowledge gaps and contentious issues $[13,19]$. On the other end of the spectrum, many scientists feel that managers should have some technical understanding of the scientific process and the ecosystems in which they are working [20]. Intellectual autonomy from management also needs to be present when carrying out scientific endeavors to ensure scrutiny, peer review, and dissent [19]. Concerns over academic integrity have often been at the forefront of the communications debate. Thus, while both the scientific and management communities have explicitly stated the need to have reciprocal communication, this has been challenging due to cultural and institutional divides. As a result, many agencies have begun to employ specific science communication experts whose sole role is to facilitate dialogue between managers and scientists.

2.2. Review of Science Management Cultural Differences. The cultural differences present in the science and management 
fields influence communications in many ways, often inhibiting comprehension of content and placing emphasis on the differing attitudes and perceptions in each area [12]. Scientists and managers who are ingrained within these cultures inherently have different concepts and understandings of natural systems and work practices [19]. Adding to these complexities are numerous differences amongst managers and scientists in the distinctive international, federal and regional agencies [12]. Conflicts between science and management have occurred because of different time and work mandates. The time limitations and restrictions placed on decision makers and the longer terms associated with scientific research create a major area of disconnect between the fields in terms of expectations, deadline creation, and outcome implementation $[7,13]$. For example, scientists rely heavily on journal publications targeted to others in their field to communicate their research. Not only do they convey their work through these publications, but their research is often communicated on the basis of long-term time frames, which often operate in years rather than months or weeks [21]. Management, on the other hand, operates in a field that is time sensitive and based in accordance with politics, leading to shorter deadlines [7]. The time scale differences are particularly challenging within EBM, where scientific assessment of entire ecosystems can take many years. Expectations have been placed on both scientists and managers to improve coordination and communication of their information when working with each other. Scientists must first write research grants and obtain funding and then present research that is publicly distributed and application oriented, while managers gain a greater understanding of the research presented to them.

\subsection{Review of Measuring Science Management Cultural}

Differences. Communication is the basic social process in which cultural senses are cultivated [22]. Within organizational studies, culture has been represented as a social factor that keeps an organization together and expresses the values and beliefs of its members [23]. These values or patterns of belief are manifested by symbolic devices that can be identified through an organizational cultural audit [24]. Science management integration within EBM can be challenging because the cultural differences of participating agencies are often not assessed. Alignment of organizational culture within both science and management is possible by reviewing work structure and systems to ensure strategic integration and communication [25]. Cultural compatibility does not necessarily mean that two organizations need to be alike but more that there is a general understanding of how the other works [24]. Considerations that should be taken into account when evaluating the cultural compatibility of science and management include the job satisfaction of individual employees, differing decision making and management methods, language, work practices, and organizational structure. The surrounding environment is also a powerful element that shapes work relationships and processes. Desk objects, bulletin board content, and employee interaction can directly reveal an organization's culture.

\section{Analysis of Science and Management Integration in the NWHI-RP}

3.1. Background of the NWHI-RP. The NWHI-RP is a collaboration between the Hawai i Institute of Marine Biology and Office of National Marine Sanctuaries, specifically with the Northwestern Hawaiian Islands Coral Reef Ecosystem Reserve and, later, the Papahānaumokuākea Marine National Monument. The Hawai'i Institute of Marine Biology (HIMB) is a research facility that focuses on marine ecosystem science and an institute in the School of Earth Science and Technology at the University of Hawai'i at Mānoa. The Northwestern Hawaiian Islands (NWHI) is a biologically diverse ecosystem, relatively free of anthropogenic impacts, making it an ideal site to study ecosystem function. In 2006, the highest level of protection possible under the United States law was afforded to the area creating the Papahānaumokuākea Marine National Monument (PMNM). Three jurisdictional agencies act as cotrustees and are responsible for the conservation of the Papahānaumokuākea Marine National Monument; they include two federal agencies, Department of Commerce (National Oceanic and Atmospheric Administration (NOAA) ) and Department of the Interior (US Fish and Wildlife), and the State of Hawaici [26]. Research has been carried out in the NWHI for many years, but the formalized partnership between HIMB and the NOAA Office of National Marine Sanctuaries was not finalized until 2005 (one year prior to the Monument designation). The Office of National Marine Sanctuaries is the trustee for the United States system of marine protected areas. The research partnership with HIMB was designed to generate data to assist decision makers using EBM. Research emphasis has included understanding connectivity through movement patterns and genetic population structures, characterizing and determining levels of coral health, mapping and monitoring ecosystem threats such as climate change, and providing education and outreach on the related science activities [27]. Prior to the partnership, existing management and science agencies did not frequently share their work in a formalized setting. The NWHI-RP has worked hard to overcome communication challenges and is a successful example of science management integration and collaborative communications. The NWHI-RP will be used as a case study applying business management models to better understand the differences within science and management. The NWHI-RP offers a unique opportunity to examine the processes that currently combine the knowledge of scientists, managers, and other support staff and make recommendations that will facilitate a more open dialogue.

3.2. Science Management Integration Project. In June 2009, the NWHI-RP began the Science Management Integration Project to identify contemporary needs and challenges including communication mechanisms for the public and science management partners within. The Science and Management Integration Team (SMIT) was a small group of eight participants comprised of managers, educators, and 
TABLE 1: Science management organizational culture analysis.

\begin{tabular}{|c|c|c|c|}
\hline & HIMB (science) & Commonalities & PMNM (management) \\
\hline $\begin{array}{l}\text { Office space } \\
\text { allocation }\end{array}$ & $\begin{array}{l}\text { Offices are spread out across many labs and } \\
\text { buildings. Very few common areas. }\end{array}$ & $\begin{array}{l}\text { Space allocation based on } \\
\text { seniority. } \\
\text { Common areas used for breaks, } \\
\text { group meetings, and so on. }\end{array}$ & $\begin{array}{l}\text { Offices more centrally located } \\
\text { next to each other. } \\
\text { Common areas are regulated by } \\
\text { importance of the event. }\end{array}$ \\
\hline $\begin{array}{l}\text { Objects and } \\
\text { signage display }\end{array}$ & $\begin{array}{l}\text { Animal field guides, scientific posters, and } \\
\text { lab publications. }\end{array}$ & $\begin{array}{l}\text { Workplace safety posters, job } \\
\text { announcements, nature pictures, } \\
\text { and maps. }\end{array}$ & $\begin{array}{l}\text { Pictures of staff, outreach } \\
\text { material. }\end{array}$ \\
\hline Communications & $\begin{array}{l}\text { Frequent verbal communication, mass } \\
\text { communication through email list serve. } \\
\text { Little written communication. } \\
\text { Two-way communication. } \\
\text { Semiformal to informal. }\end{array}$ & $\begin{array}{l}\text { Written and verbal. } \\
\text { Frequent use of email. }\end{array}$ & $\begin{array}{l}\text { Less verbal communication } \\
\text { except for offices in close } \\
\text { proximity. } \\
\text { One-way communication. } \\
\text { Formal. }\end{array}$ \\
\hline Social interaction & $\begin{array}{l}\text { Frequent and casual interactions. Flexible } \\
\text { work environment with nonfinancial } \\
\text { rewards (e.g., travel and work in remote } \\
\text { ecosystems like the Northwestern Hawaiian } \\
\text { Islands). } \\
\text { Lower turnover in staff. }\end{array}$ & & $\begin{array}{l}\text { Infrequent and formal } \\
\text { interactions. } \\
\text { Unpredictable schedule, crisis } \\
\text { management. } \\
\text { Formal government } \\
\text { environment. } \\
\text { Higher staff turnover. }\end{array}$ \\
\hline
\end{tabular}

scientists spanning a variety of seniority levels. The team was responsible for participation in focus groups pertaining to the organizational structure, partnership culture, and recommendations to better integrate science and management within the partnership. The overarching goal of the project was to develop a resource that would improve communications between the science and management institutions of the NWHI-RP. Several methods of evaluation were used in this project to develop a full analysis and case study. The science management evaluation was a year-long study conducted within three phases to collect information, analyze, and produce recommendations. Several types of analyses were completed including a literature review, attitudes and perceptions survey, focus groups, and organizational analyses (including a Strengths Weaknesses Opportunities Threats (SWOT) analysis, organizational culture analysis, and organizational structure evaluation). This paper will explore the organizational culture analysis and structure evaluation, which are two components of a larger study evaluating the NWHI-RP.

3.3. Partnership Culture. The differences in science and management culture often inhibit understanding and challenge integration of the two areas. The idea of assessing organizational culture focuses attention on the qualitative influences or shared frames of reference among entities [23]. Differences between science and management can inhibit comprehension of content and place undue emphasis on differing attitudes, perceptions, and prejudices [12]. Organizational culture can be assessed in a variety of ways using observations, interviews, or questionnaires [24]. It is important to examine where cultural similarities exist between HIMB and PMNM in order to understand where integration can be implemented.
The SMIT was tasked with assessing the organizational culture of the NWHI-RP by observing four different elements of each agency. The similarities and differences were compared against several attributes including interoffice communications, social relations, office space allocation, signage display, and any other related observations (see Table 1). Commonalities were shown between HIMB and PMNM related to shared area use and workplace displays. Both agencies differed in their space allocation, which influenced how partners interacted with each other. PMNM resides in two office buildings, while HIMB has wide-spread offices and labs across an island approximately 29 acres in size. Other differences in organizational culture were apparent in the methods of social interaction and message styles employed by the members of each community. An informal and verbal communication approach was common at HIMB, while a more formalized and written process was emphasized by PMNM.

The results shown in Table 1 are consistent with the current literature, reflecting differences in science and management communication styles. All of the attributes discussed above contribute to the makeup of each agency and the dynamics within the NWHI-RP. These attributes are significant but are not the sole factors in measuring the effectiveness of a partnership. Cultural audits are rarely conducted in EBM but are important so that partnerships have an understanding of the similarities and differences within each agency involved. Once cultural differences are identified, attempts to decrease gaps between science and management can be made. Much of this is echoed in the analysis of the organizations structures as well.

3.4. Partnership Structure. The structure of an organization will dictate how people communicate and accomplish tasks 
[28]. Drawing from business models, there are three basic types of structures that commonly occur in organizations and include hierarchical, flat, or matrix [29]. A hierarchical organization is a traditional structure with authority heavily weighted at the top and layers of workers and support staff below with each subsequent layer having less autonomy than the preceding one [29]. A flat or horizontal organization has authority spread evenly throughout the entire structure, with little or no management between workers fully involved in decision-making processes [29]. Lastly, a matrix organization pools employees and assigns duties based on particular projects [29].

As part of the science management integration assessment, the structures of both NWHI-RP entities were analyzed in order to understand how communications lines were influenced by organizational structure. Development of partnership structure was based on the SMIT analysis and employee staff listings provided. Differences in structure occurred depending on individual perceptions. HIMB, the science entity of the partnership, was identified as having a horizontal organization because of the autonomy given to scientists to pursue work in their specific research area. PMNM, the management side, was characterized as a hierarchical organization, common to government agencies. Since both partnership organizations were shown to have different structures, it is necessary to look at the communication processes between the two.

The horizontal structure of HIMB is influential on how scientists participate in the organization and the opportunities that are afforded to staff to provide input on partnership choices and research. Lead administration at HIMB seeks input from principal investigators in order to make science decisions. However, HIMB has little lateral exchange on specific projects despite the efforts to maintain a flat structure. Some of this is influenced by the differences in research areas from the participating scientists. Organizational differences between the two agencies are mostly found between the support positions and job duties. Differences in organizational expectations contribute directly to job types and job satisfaction. Single versus multiple task positions can influence the work scope and scale. Within HIMB, there is more project-oriented work, which leads to specific knowledge development and focus. In the PMNM offices, multitask work scales are more common, leading to varied work plans and numerous projects.

Both HIMB and PMNM are in a continuous state of evolution, and their organizational structure is a main source of change and restructuring. Partnership communication between the management and science agencies is most frequently done at the administration level between the HIMB director, the lead partnership coordinator, and the PMNM superintendents. Several communication gaps were demonstrated by this analysis, particularly between staff within each agency and across the partnership. For example, during the field season, scientists must coordinate with each other and with management staff on topics relating to permit applications, research, and field logistics. Individuals who hold responsibility for numerous projects are often difficult to reach. This problem represents one of the biggest communication obstacles that the partnership is faced with. Over the past few years, expansion in staff positions has aided with the work load allowing for better communication.

\section{Partnership Communications}

To compensate for the changing dynamics and differing organizational structures, planned mechanisms for partnership interaction and communication have been instituted to ensure integration of science into management. Communication of partnership activities occurs regularly as a result of symposia and informal meetings, semiannual reports, and outreach.

4.1. Symposia and Meetings. Presentations regarding the scientific research in the Northwestern Hawaiian Islands are delivered to managers and other partners semiannually through two-day symposia. This opportunity allows scientists and managers to come together to review the science, ask questions, and elaborate on any related issue or management concern. Within the NWHI-RP, scientists have learned to develop their presentation skills for management audiences, breaking down research to apply to management needs. Infrastructure has been set up through the partnership to assist with this using media training and "brown-bag" lunch presentations to facilitate communication between the management and science agencies. Managers have adapted to this as well, communicating on a more frequent basis their expectations and information needs. As the partnership science continues to develop, more participants and spectators are attending these meetings, widening the collaboration and discussion of science and management. Inbetween symposia, smaller semiannual meetings are held to provide updates to a more direct group. Quarterly lectures are another technique used for bringing together science and management partners. One-hour presentations during lunch are given from both managers and scientists to update the group on relevant issues related to the partnership. A variety of subject matters have been covered from research cruise planning, student presentations, to science-policy roundtable discussions. These meetings allow partnership participants to interact with each other and communicate in an informal setting.

4.2. Semiannual Reports. From the NWHI-RP symposia and meetings, the research is then translated into a semiannual report that is distributed to managers, related federal agencies and other partners. As more information is generated, the demand for the report has grown. Scientific findings are reiterated in a condensed and digestible format removing technical language and including illustrations and project summaries for easier reading. The report originally was produced quarterly and now alternates between a more thorough annual edition and a brief newsletter. The decrease in coverage frequency has allowed for more detailed reporting and better accommodates the timeframe associated with 


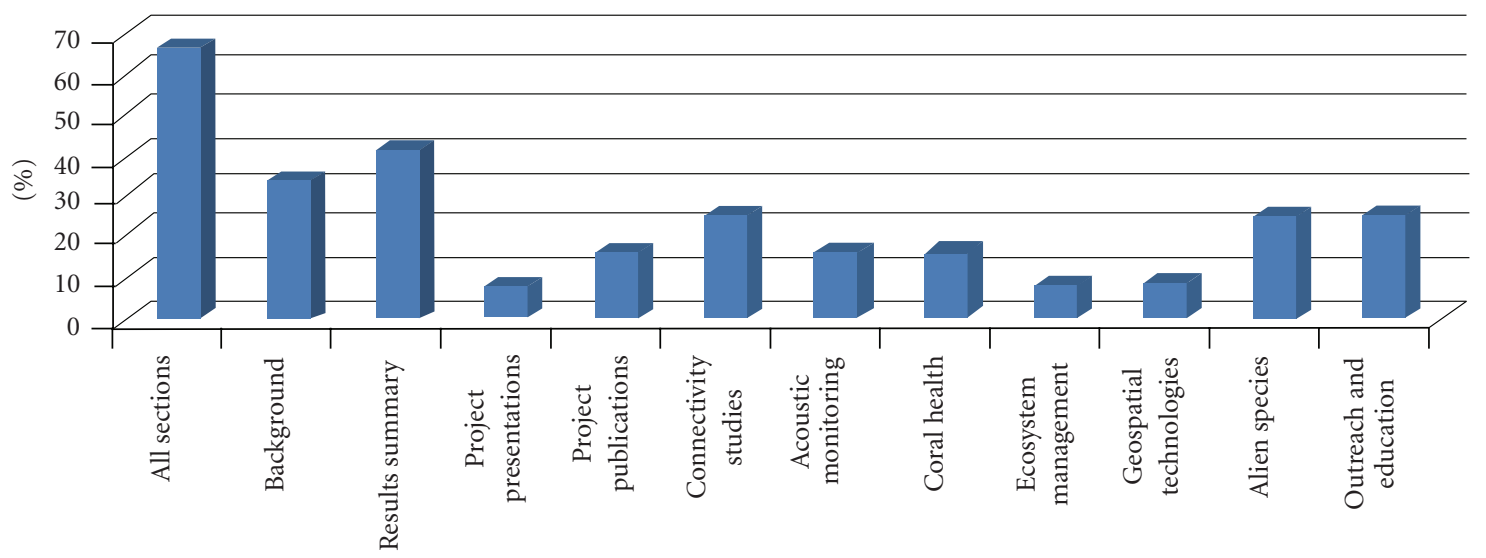

Section read

FIGURE 1: HIMB NWHI research partnership semiannual report sections read. (Survey participants had the option of selecting more than one section with the exception of those who selected all sections.)

TABLE 2: The NWHI-RP communications methods since 2007 for management, public, and elementary school audiences.

\begin{tabular}{|c|c|c|c|c|c|}
\hline \multicolumn{2}{|c|}{ Management } & \multicolumn{2}{|c|}{ Public } & \multicolumn{2}{|c|}{ Elementary school } \\
\hline Method & Numbers & Method & Numbers & Method & Numbers \\
\hline $\begin{array}{l}\text { Semiannual meetings } \\
\text { and symposiums }\end{array}$ & $\begin{array}{l}6 \text { events } \\
477 \text { people }\end{array}$ & Continuing education & $\begin{array}{l}6 \text { courses } \\
104 \text { people }\end{array}$ & $\begin{array}{l}\text { Elementary school } \\
\text { (i) teacher workshops } \\
\text { (ii) career days } \\
\text { (iii) marine } \\
\text { curriculum }\end{array}$ & $\begin{array}{l}27 \text { events } \\
9,242 \text { people }\end{array}$ \\
\hline $\begin{array}{l}\text { Brown bag lectures } \\
\text { and round table } \\
\text { discussions }\end{array}$ & $\begin{array}{l}19 \text { events } \\
736 \text { people }\end{array}$ & Family education & $\begin{array}{l}27 \text { events } \\
6774 \text { people }\end{array}$ & $\begin{array}{l}\text { Ecosystem Penpals } \\
\text { Student Exchange } \\
\text { Project }\end{array}$ & $\begin{array}{l}4 \text { teachers } \\
70 \text { students }\end{array}$ \\
\hline $\begin{array}{l}\text { Semiannual research } \\
\text { reports }\end{array}$ & $\begin{array}{l}6 \text { reports } \\
984 \text { people }\end{array}$ & $\begin{array}{l}\text { General public } \\
\text { (i) science tables at } \\
\text { community events } \\
\text { (ii) evening lectures }\end{array}$ & $\begin{array}{l}25 \text { events } \\
8,831 \text { people }\end{array}$ & $\begin{array}{l}\text { Future Marine } \\
\text { Scientist Mural } \\
\text { Painting Project }\end{array}$ & $\begin{array}{l}3 \text { teachers } \\
152 \text { students }\end{array}$ \\
\hline No. of people & 2,197 & No. of people & 15,709 & No. of people & 9,471 \\
\hline & & Total no. of people rea & ce 2007) 27,377 & & \\
\hline
\end{tabular}

scientific studies. In December 2008, an anonymous evaluation was conducted to determine if readers were finding the report information clear and transferable to management. According to the survey, $67 \%$ of respondents read all the sections within the report. The activity summaries and partnership background were ranked as the easiest sections to comprehend and were the most frequently read (see Figure 1). All survey respondents agreed that the report was useful and informative, with $75 \%$ stating that they were dependent on the report for research updates. Respondents also stated that the report language "appropriately reflected their level of scientific understanding." Evaluations were positive, but criticisms concerning the "lack of focus on future direction" and "management implications" were also cited. This echoes the continued need for inclusion of management applications to the science presented.

4.3. Outreach. Within the partnership, scientists have been able to present their research to both managers and the public, while simultaneously producing peer-reviewed publications. Since 2007, studies from the partnership have been shared with over 27,000 people through public events, class presentations, and community involvement (see Table 2). (The outreach information presented here reflects the education efforts related to the NWHI-RP only from the HIMB and does not include the multitude of outreach and education related to the PMNM.) Over 50 undergraduate and graduate students at HIMB have also been supported through the NWHI-RP. Many of these students have been involved in outreach through the partnership gaining experience in sharing their research with the public and speaking to general audiences. The NWHI-RP has implemented several communication plans to ensure that the marine science being conducted in the PMNM is applicable to both management and the public. Science concepts are included with interdisciplinary outreach programs to build public involvement. Encouraging community to cultivate a sense of place in the partnership, and this unique ecosystem, requires 
the development of programs that bridge relationships with local schools and neighborhoods. The outreach effort implemented by the NWHI-RP has successfully accomplished this.

\section{Recommendations for Improved Communication}

Following the literature review, organizational analysis and cultural evaluation of the NWHI-RP, a few recommendations have been made from the SMIT to improve communication between managers and scientists. While these recommendations are targeted at the NWHI-RP, they can easily be applied to other EBM partnerships or science agencies. Few recommendations for science management integration within EBM have been made in the literature aside from better communications training for scientists and incorporating management needs into science results. These are important aspects of science management integration but fail to provide any practical examples or recommendations to accomplish this. Using the existing outreach efforts, the NWHI-RP has been able to improve its overall communications. Further development of programs and analysis through the science management integration project will allow for continued improvement in communication.

Existing collaboration and communication efforts within the NWHI-RP has improved productivity by fostering employee relations and awareness of each other's work. While the partnership has been successful at implementing several communication methods, further collaboration should be encouraged. Two-way communications has been cited as one of the greatest challenges in $\mathrm{EBM}[6,13,18]$, but regular interactions in the partnership have already shown to create a positive mechanism for partnership communications. It is recommended that the semiannual meetings and symposia incorporate more group discussion and creative brainstorming sessions on key management issues. In order to facilitate more efficient communication in the partnership, one meeting per year should be dedicated to presenting science and management results and another one for group discussion. There should also be greater emphasis on balancing the presentations to include more management-orientated concepts and concerns. Another way to encourage further discussion through informal communication is by organizing gatherings outside of work to discuss specific science topics.

The NWHI-RP semiannual reports have already undergone revision based on the evaluation that was completed in February 2009. Science reporting is an important component of the research occurring through the partnership and EBM in general. Science writing needs to be readable by both managers and nonscience audiences. Critical to understanding research, a science glossary with key terms and a species index were added to the semiannual reports. This allowed for general understanding of the terminology without losing the important components of the research. Inclusion of a section on management activities and describing management implications of the research is still needed to better integrate the partnership literature. The recognition and promotion of the NWHI-RP amongst the public is also essential to the support and understanding of research and both the HIMB and PMNM agencies. As research projects are completed, publications and media releases targeted at the general population should be encouraged. Continued participation at public events both related and unrelated to marine science and conservation will also help to increase partnership recognition. Community fairs, concerts, and fishing tournaments are all excellent places to share information about science and management initiatives.

\section{Conclusion}

The science management integration analysis conducted on the NWHI-RP is an effective way of evaluating EBM partnership communications and science management integration. Using techniques such as organizational analysis and surveys, evaluation of how science, and management interact can be vital to the success of science management partnerships. The NWHI-RP is a pragmatic example of an evolving EBM partnership that continues to improve its communication and ability to integrate science and management. For over five years, HIMB and PMNM have been working together to use ecosystem-based science to inform management and develop integrative research. The lessons learned provide a starting point for other management and science groups looking to support EBM. To further improve on this successful model, the NWHI-RP has implemented the Science Management Integration Project to identify contemporary needs and challenges including communication mechanisms for the public and science management partners within. As outlined here, the partners use several different modes of inquiry and presentation in its science communications plans with both management and the public to meet the multidisciplinary needs of EBM. Challenges in science communications with the partnership and EBM in general continue to exist, but by improving our understanding of both the science and management disciplines, the deficiencies in these fields are eroded, and this paper highlights a successful model for collaborative communication and the integration of science and management.

\section{Acknowledgments}

The authors acknowledge the support of NOAA's Office of National Marine Sanctuaries, the Papahānaumokuākea Marine National Monument, State of Hawai'i Department of Land and Natural Resources Division of Aquatic Resources, US Fish and Wildlife Service, NOAA Pacific Islands Fisheries Science Center, NOAA National Marine Sanctuaries Program Pacific Islands Region, and the numerous University of Hawai' $i$ partners involved in this project. Funding was provided by NMSP MOA 2005-008/6882. Support for the Science Management Integration Project would not have been made possible without the work of the Science Management Integration Team and Tetra Tech Clancy Environmental especially David Graham. The authors of this paper are 
grateful to the editors and reviewers of the journal whose comments resulted in a better paper.

\section{References}

[1] K. L. McLeod, J. Lubchenco, S. R. Palumbi, and A. A. Rosenberg, "Communication partnership for science and the sea scientific consensus statement on marine ecosystem-based management," 2005, http://www.compassonline.org/.

[2] S. R. Palumbi, Marine Reserves: A Tool for Ecosystem Management and Conservation, Pew Ocean Commissions, Arlington, Va, USA, 2002.

[3] U.S. Commission on Ocean Policy, An ocean blueprint for the 21st century, U.S. Commission on Ocean Policy, Washington, DC, USA, 2002, Final Report.

[4] H. M. Leslie and K. L. McLeod, "Confronting the challenges of implementing marine ecosystem-based management," Frontiers in Ecology and the Environment, vol. 5, no. 10, pp. 540$548,2007$.

[5] The White House Council on Environmental Quality, "Final Recommendations of the Interagency Ocean Policy Task Force,” July 2010, http://www.whitehouse.gov/files/documents/OPTF_Final Recs.pdf

[6] E. A. Graffy, "Meeting the challenges of policy-relevant science: bridging theory and practice," Public Administration Review, vol. 68, no. 6, pp. 1087-1100, 2008.

[7] A. T. Bielak, A. Campbell, S. Pope, K. Schaefer, and L. Shaxson, "From science communication to knowledge brokering: the shift from science push to policy pull," in Communicating Science in Social Contexts: New Models, New Practices, D. Cheng, M. Claessens, N. R. Gascoigne, J. Metcalfe, B. Schiele, and S. Shi, Eds., pp. 201-226, Springer, London, UK, 2008.

[8] B. B. Bingham, R. E. Bennetts, and A. Hubbard, "Integrating science and management: the road to Rico-Chico," The George Wright Society, vol. 24, no. 2, pp. 21-25, 2007.

[9] M. T. Barbour, N. L. Poff, R. H. Norris, and J. D. Allan, "Perspective: communicating our science to influence public policy," Journal of the North American Benthological Society, vol. 27, no. 3, pp. 562-569, 2008.

[10] D. W. Cash and S. C. Moser, "Linking global and local scales: designing dynamic assessment and management processes," Global Environmental Change, vol. 10, no. 2, pp. 109-120, 2000.

[11] J. Endter-Wada, D. Blahna, R. Krannich, and M. Brunson, "A framework for understanding social science contributions to ecosystem management," Ecological Applications, vol. 8, no. 3, pp. 891-904, 1998.

[12] P. Quevauviller, P. Balabanis, C. Fragakis et al., "Science-policy integration needs in support of the implementation of the EU Water Framework Directive," Environmental Science and Policy, vol. 8, no. 3, pp. 203-211, 2005.

[13] J. Taussik and Y. Gilbert, "Communication in coastal management: scientists and managers," in Proceedings of the 6th International Conference of the EUROCOAST \& EUCC The Coastal Union (Littoral '02), pp. 3-13, Porto: Portugal, September 2002.

[14] L. Morgan, W. Chandler, E. Douce, S. Brooke, J. Guinotte, and S. Myhre, "Research priorities for the Pacific Remote Islands Marine National Monument," Research report by the Marine Conservation Biology Institute (MCBI), 2010, http://www.mcbi.org/publications/publications.htm.
[15] L. K. Bergen and M. H. Carr, "Establishing marine reserves: How can science best inform policy?" Environment, vol. 45, no. 2, pp. 8-19, 2003.

[16] NOAA Coral Reef Conservation Program, "Roadmap for the Future: A Plan for Developing CRCP Direction Through 2015," July 2008, http://coralreef.noaa.gov/aboutcrcp/strategy/reprioritization/roadmap/resources/crcproadmap.pdf.

[17] M. T. Imperial, "Institutional analysis and ecosystem-based management: the institutional analysis and development framework," Environmental Management, vol. 24, no. 4, pp. 449-465, 1999.

[18] R. Lamberts and S. Stocklmayer, "Science communication for scientists: experiences from Australia," in Public Communication of Science and Technology Working Symposium, Beijing, China, 2005.

[19] D. Luttenberg and D. Scavia, "Scientific input to coastal management and policy: three models of communication," in Proceedings of the 16th International Conference of the Coastal Society, pp. 9-16, NOAA Coastal Ocean Program, Williamsburg, Va, USA, 1998.

[20] R. N. Clark, E. E. Meidinger, G. Miller et al., "Integrating science and policy in natural resource management: lessons and opportunities from North America," Tech. Rep. PNWGTR-441, United States Department of Agriculture, Forest Service, Pacific Northwest Research Station, Portland, Ore, USA, 1998.

[21] H. P. Peters, H. Heinrichs, A. Jung et al., "Medialization of science and political relevance," in Communicating Science in Social Contexts: New Models, New Practices, D. Cheng, M. Claessens, N. R. Gascoigne, J. Metcalfe, B. Schiele, and S. Shi, Eds., pp. 71-92, Springer, London, UK, 2008.

[22] D. Carbaugh, "Naturalizing communication and culture," in The Symbolic Earth: Discourse and our Creation of the Environment, J. Cantrill and C. Oravec, Eds., pp. 38-57, University of Kentucky Press, Lexingtion, Ky, USA, 1996.

[23] L. Smircich, "Concepts of culture and organizational analysis," Administrative Science Quarterly, vol. 28, no. 3, pp. 339-358, 1983.

[24] S. Cartwright and C. Cooper, "The role of cultural compatibility in successful organizational marriage," Academy of Management Executive, vol. 7, no. 2, pp. 57-70, 1993.

[25] C. McNamara, Field Guide to Consulting and Organizational Development, Authenticity Consulting, LLC, Minneapolis, Minn, USA, 1998.

[26] L. LaFrance and J. N. Kittinger, "Governing large-scale marine protected areas: protection of the Northwestern Hawaiian Islands," in Proceedings of the International Marine Conservation Congress, George Madison University, Fairfax, Va, USA, 2010, http://www.allacademic.com/meta/p296249_ index.html.

[27] R. Toonen, J. Leong, and C. Wiener, Hawai'i Institute of Marine Biology semi-annual report XII, University of Hawai'i, Honolulu, Hawaii, USA, 2010.

[28] P. F. Drucker, People and Performance: The Best of Peter Drucker on Management, Harper's College Press, New York, NY, USA, 1977.

[29] M. Harris and A. Raviv, "Organization design," Management Science, vol. 48, no. 7, pp. 852-865, 2002. 

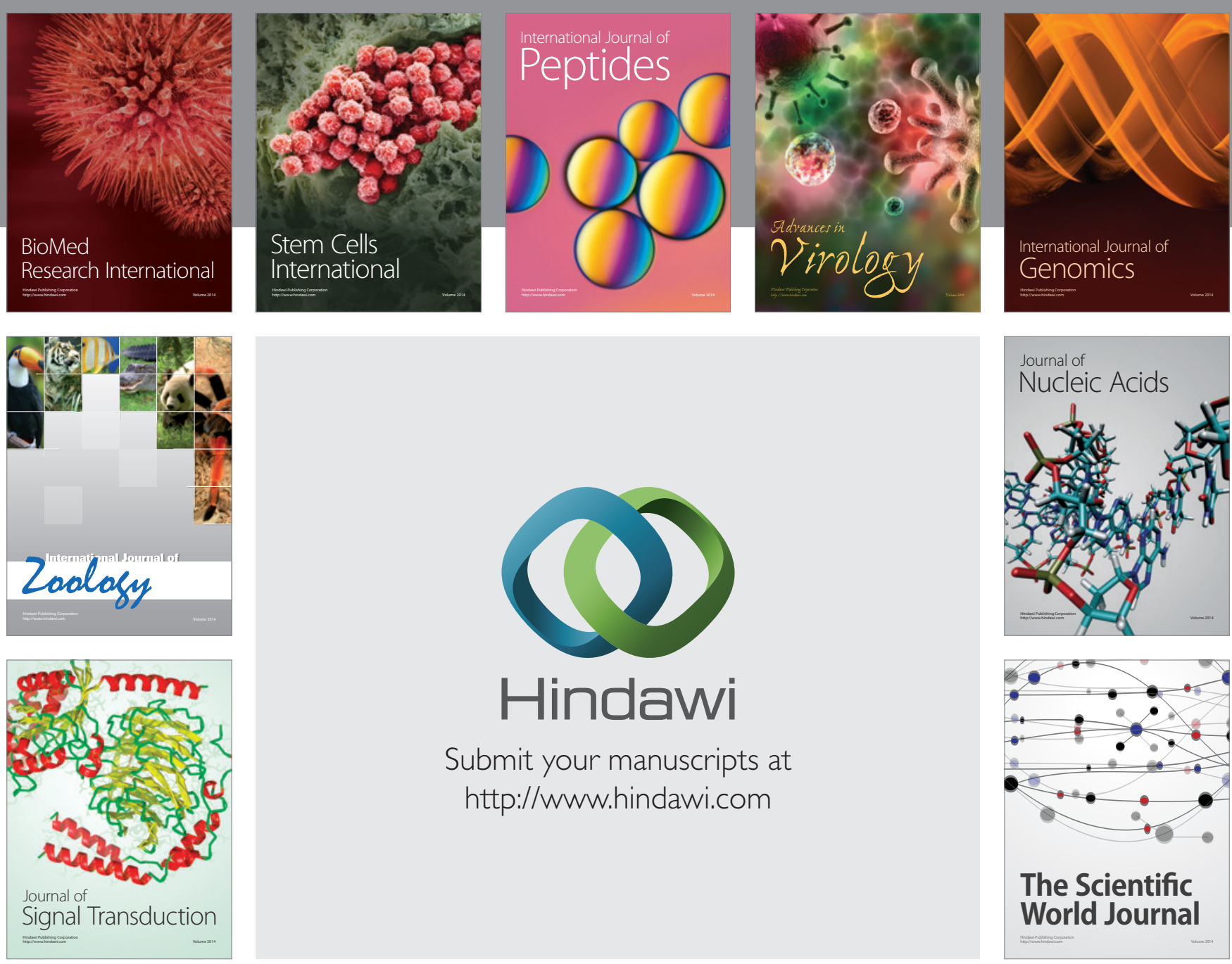

Submit your manuscripts at

http://www.hindawi.com
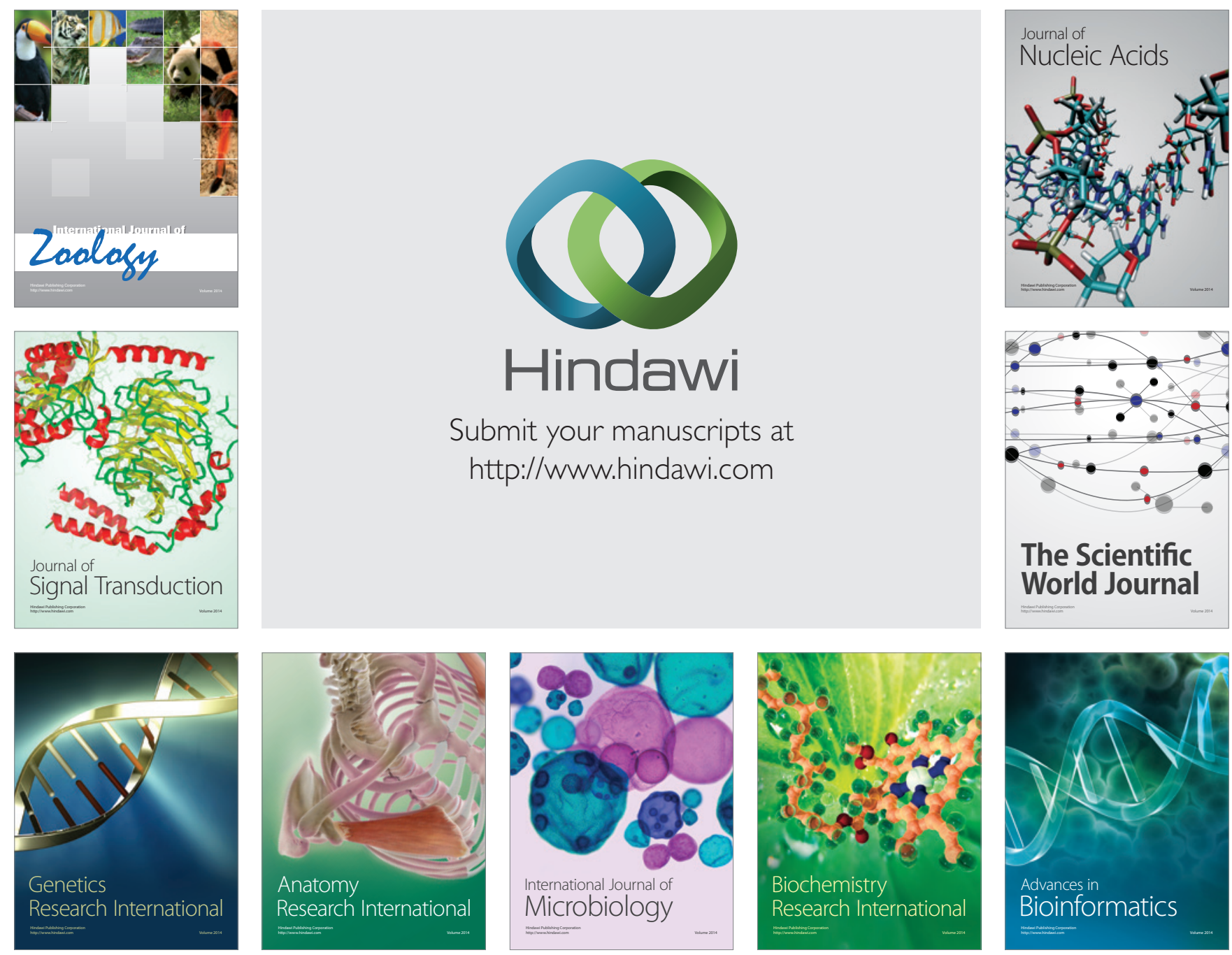

The Scientific World Journal
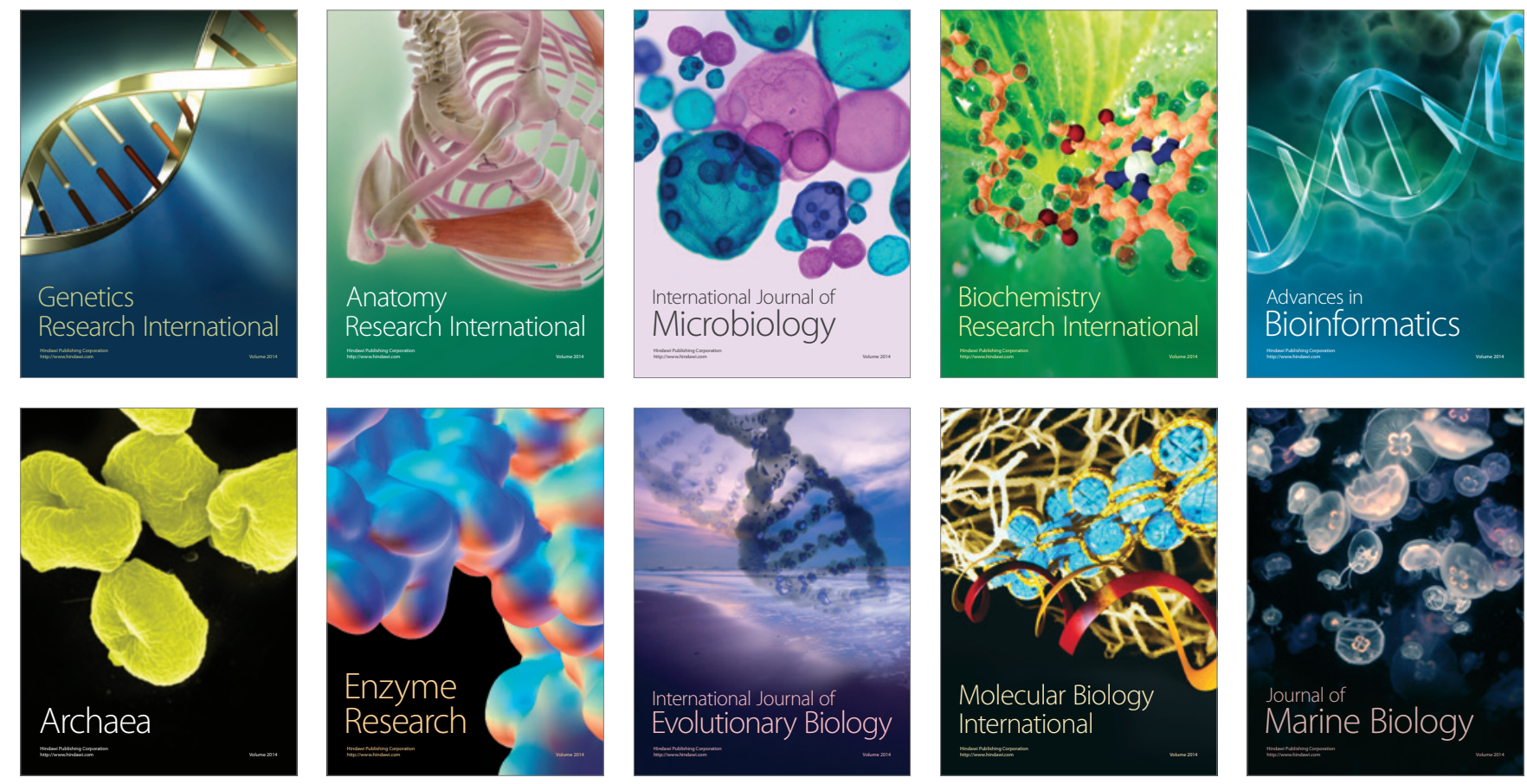